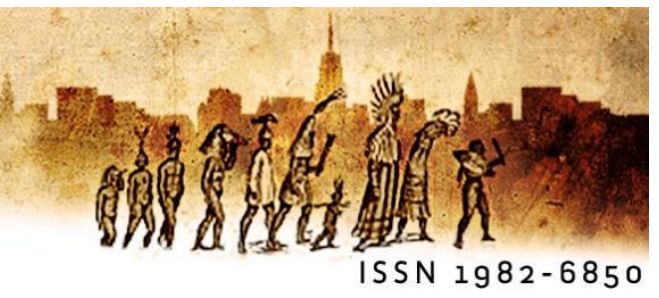

\title{
Algumas considerações sobre a presença de elementos ecológicos na poesia brasileira contemporânea
}

\section{Considerations on the presence of ecological elements in contemporary Brazilian poetry}

\author{
Mariana Cristina Pinto Marino (UFPR) \\ Yuri Amaury Pires Molinarii (UFPR)
}

Resumo: A crise ambiental, há décadas instaurada no mundo, tem suscitado reflexões de diferentes ordens (sendo elas de cunho artístico, filosófico, antropológico), mais especificamente a partir da década de 1960, com a insurgência de movimentos ambientalistas e preservacionistas. Tendo, então, a discussão sobre ecologia adentrado as mais diferentes áreas, como nas humanas, os (re)pensares do mundo e da vida a partir da perspectiva ecológica têm ressoado na poesia contemporânea brasileira em diferentes graus de engajamento. Pretende-se, portanto, apresentar e discutir aspectos ecológicos encontrados em obras de Ana Martins Marques, Sérgio Medeiros, Jussara Salazar e Vinícius Lima, a fim de levantar aspectos formais e temáticos que enriqueçam o debate ecológico na poesia.

Palavras-chave: Ecologia; Ciências Humanas; Poesia brasileira contemporânea.

\begin{abstract}
The environmental crisis, established in the world for decades, has given rise to reflections of different orders (of artistic, philosophical and/or anthropological nature), more specifically since the 1960s, with the insurgency of environmentalist and preservationist movements. Discussion about ecology having entered the most different areas, as in the humanities, the (re) thinking of the world and of life from the ecological perspective has resonated in contemporary Brazilian poetry in varying degrees of engagement. It is intended, therefore, to present and discuss ecological aspects found in works by Ana Martins Marques, Sérgio
\end{abstract}


Medeiros, Jussara Salazar and Vinícius Lima, in order to raise formal and thematical aspects that enrich the ecological debate in poetry.

Keywords: Ecology; Human Sciences; Contemporary Brazilian poetry.

\section{Introdução}

"A minha provocação sobre adiar o fim do mundo é exatamente sempre poder contar mais uma história". É a partir desse pensamento de Krenak (2019, p. 27) que pretendemos discutir como uma parcela da poesia brasileira - mais especificamente, a contemporânea - está comprometida com a questão ambiental, em maior ou menor escala, a partir da evocação de elementos ecológicos, do repensar de uma ideia ecológica construída a partir de uma perspectiva romântica da natureza e, particularmente, da atualização desses pontos de vista em relação ao meio natural para a realidade do Antropoceno ${ }^{1}$.

Mais do que observar questões relacionadas às consequências da exploração ambiental nas autoras e autores selecionados, o intuito de pensar a ecologia dentro da literatura, de um modo geral, ultrapassa as questões simplesmente relacionadas às óbvias desdobradas por esse amplo assunto: a intenção, então, é, além de identificar presenças constantes de elementos de composição do meio natural nos trabalhos poéticos, levantar tensões relacionadas à dicotomia natureza versus cultura, observar as dinâmicas entre seres humanos e não-humanos nas narrativas poéticas, além de compreender como funcionam os traços de temporalidade construídos pelas e pelos poetas. Além disso, há que se debater aspectos de um possível enfraquecimento da noção antropocêntrica de organização do mundo, e como se dão as possíveis visões ecocêntricas ou biocêntricas presentes nas narrativas poéticas que adiam o fim do mundo, exatamente por não se resumirem a contar somente histórias calcadas numa visão apocalíptica das relações entre seres humanos e não-humanos - o que, de fato, contribui para a discussão mais profícua

\footnotetext{
${ }^{1}$ A teoria do Antropoceno, inicialmente pensada pelo campo da geologia, além de figurar como uma possível nova era geológica, pode corresponder também ao momento histórico e cultural dominado pela atividade humana (em níveis industriais, tecnológicos, econômicos, exploratórios).
} 
do que pode ser feito para repensar políticas desenvolvimentistas calcadas numa falsa ideia de progresso.

Muito se discute acerca da relevância de estabelecer relações entre ecologia e literatura - áreas que, num primeiro momento, parecem não convergir. No entanto, dada a importância das discussões preconizadas pelos movimentos ambientais desde a década de 1970, assim como a urgência do debate nas esferas governamentais, acadêmicas e sociais (através de movimentos sociais organizados que ocorreram não somente no Ocidente), a teoria literária não estava isenta de ser afetada por esses desdobrares: a partir da entrada de perspectivas interdisciplinares no campo narratológico, é inevitável que se comece um movimento a fim de solidificar o entrelaçamento entre literatura e ecologia. Assim, na última década do século XX surge, nos Estados Unidos, uma abordagem denominada Ecocrítica que, "grosso modo, é o estudo das relações entre literatura e ambiente físico" (GLOTFELTY, 1996, p. xviii). Como abordagem teórico-metodológica, a Ecocrítica pode ser englobada, atualmente, nos chamados Environmental Studies ou Envrironmental Humanities, um campo acadêmico multidisciplinar que conecta princípios das ciências sociais, físicas e econômicas a fim de refletir sobre as complexidades das questões ambientais contemporâneas. Sobre isso, pode-se dizer que, a partir de mais de uma década de produções interdisciplinares voltadas à compreensão dessas problemáticas, há uma tentativa de conjunção (também metodológica33) do que seria considerado um pensamento ecológico crítico, apesar da existência, como se sabe, de diversas posturas e filosofias ecológicas. De um modo geral, a noção que busca embasar esses diferentes estilos de crítica "é a investigação das relações entre o humano e o não humano, dela fazendo parte toda

\footnotetext{
${ }^{2}$ No original em inglês, "Simply put, [ecocriticism] is the study of the relationship between literature and the physical environment". Tradução nossa.

${ }^{3}$ Para Glotfelty (1996), esse terceiro estágio, de sistematização de uma metodologia, ainda não foi alcançado pela Ecocrítica. Autores como Terry Gifford (2009) e Simon C. Estok (2009) analisam essa falta de sistematização, o que faz com que essa perspectiva de análise ainda seja vista meramente como um recorte temático. Portanto, para que sejam estabelecidas categorias ecocríticas de análise mais precisas, até mesmo no que tange à atuação desse pensamento no Brasil, Gifford assinala a importância de utilizar obras brasileiras para a construção mais profícua desse pensamento no país.
} 
uma crítica da própria palavra 'humano' ou 'homem', 'natureza' e 'civilização'" (BICCA, 2018, p. 162). Além disso, no âmbito do discurso da pós-modernidade (ou contemporaneidade), discussões sobre "globalização, feminismo, pós-colonialismo, à esfera das reflexões físico-químicas, geológicas e biocinéticas" (ibidem) são levantadas.

Isto posto, é de objetivo deste artigo apresentar e discutir poéticas ecologicamente orientadas, mesmo que as poetas e os poetas aqui apresentados não necessariamente tenham suas obras enquadradas em uma tradição ecopoética, ou não apresentem o pensamento ecológico guiando mais contundentemente seus projetos de escrita per se. Ainda assim, pode-se perceber (em maior ou menor grau de interesse de discussão) noções investigativas nas relações entre humanos e nãohumanos e seus desdobramentos, direcionamentos anteriormente apontados na voz de Bicca (2018).

Dado o escopo do presente trabalho, salientamos que um importante nome da poesia brasileira contemporânea associado a uma tendência ecológica - Leonardo Fróes - não será abordado nas páginas a seguir. Isso deve ao fato de já existirem ao menos dois estudos de maior fôlego que investigam a relação do poeta e sua obra com a natureza, e aos quais remetemos desde já. Silva Júnior (2016), em sua tese de doutorado, debruça-se sobre o mundo natural e o sagrado na obra de Fróes; Souza Junior (2006), por sua vez, situa o poeta em uma linhagem poética beat para então apurar os reflexos de uma identificação ontológica com a natureza, sempre em paralelo com Gary Snyder. Ademais, questões bastante pertinentes acerca dessa temática são explicadas pelo próprio poeta em uma entrevista concedida a Alberto Pucheu, Ricardo Lima e Sérgio Cohn na Revista Azougue, em 2003 (ver Referências).

\section{Ana Martins Marques: reencantamento pela aproximação e temporalidade ecológica}

Ana Martins Marques é uma poeta cujo trabalho, geralmente, não é reconhecido pelos envolvimentos com temáticas da natureza. Apesar de serem 
facilmente encontrados elementos naturais em sua poética, eles são apresentados de modo a assinalar situações da cotidianidade, bastante marcada por uma tensão entre o que está dentro e o que está fora: fala-se sobre um interior particular, um exterior dominado pelos elementos do mundo; indicam-se linhas geográficas e imaginárias acerca dos limites dos espaços privados e públicos, locais e estrangeiros. Como na série Arquitetura de Interiores, presente em A vida submarina (2009), primeiro livro da autora, cômodos de uma casa são acessados até se chegar à porta, "e já se está do outro lado", no jardim. Os poemas subsequentes a "jardim", que ainda compõem a série Arquitetura de interiores, levam o nome de dois mobiliares facilmente encontrados no espaço interior da casa, "guarda-roupa" e "mesa", atribuindo à série, então, uma espécie de entra-e-sai desse espaço domiciliar - uma tensão que a poeta explorará com bastante profusão em sua última obra publicada, O Livro dos Jardins (2019), que, diferentemente das anteriores ${ }^{4}$, apresenta um projeto ecologicamente interessado, a começar por sua proposta gráfica e composição de materiais5. Para Ana Martins Marques, em entrevista à Revista Bravo! (2019) sobre $O$ Livro dos Jardins,

estamos às voltas com o espaço diminuto do jardim, que é uma espécie miniatural e doméstica de natureza, um espaço limítrofe entre a casa e a rua, um espaço natural moldado pelo trabalho das mãos humanas (que, no entanto, acaba, como tudo o que é vivo, escapando um tanto do controle das mãos humanas)... (MARQUES, 2019)

\footnotetext{
${ }^{4}$ Nas obras anteriores de Ana Martins Marques, encontra-se uma diversidade de temáticas que compõem os poemas. Já $O$ Livro dos Jardins conta com "cerca de 20 poemas curtos, que giram de alguma forma em torno do universo das plantas, das flores ou dos jardins" (MAROUES, 2019), nas palavras da autora.

${ }^{5}$ O Livro dos Jardins, publicado em 2019 pela Editora Quelônio, foi impresso e costurado à mão. As edições contam com número de exemplares reduzido devido a isso (a $2^{\text {a }}$ reimpressão, por exemplo, é composta por 800 livros). O papel é feito de folhas de bambu verde e, nas palavras da autora, "Achei bonito o fato de o papel, que é bem rústico, deixar ver sua origem vegetal, como um lembrete de que os livros um dia foram árvores" (MAROUES, 2019). Além disso, o livro acompanha um marcador de páginas feito com papel de semente de camomila, o que possibilita o plantio, como sugerido, em um jardim.
} 
Ao serem apresentados tipos de jardim e também plantas, a partir dessa lógica espacial ambivalente, de limite entre o que está dentro e o que está fora, a autora suscita reflexões acerca de manejo humano de plantas que compõem esses pequenos espaços, e aproxima as vozes poéticas, por muitas vezes, de um reencantamento em relação à natureza, que pode estar ligado ao trabalho braçal árduo - como pode ser visto no décimo segundo poema, sem título, da primeira parte da obra ("É um trabalho pesado,/ o cheiro escuro da terra/ pesa nos pulmões") - ou ao simples reconhecimento de que alguns ciclos naturais independem da ação humana para acontecer ("E no entanto as plantas continuam sem mim/ vivem e morrem sem mim"). Independentemente do teor do reencantamento, ele ocorre porque há, assim como na questão espacial e limítrofe do jardim, uma outra tensão reconhecida: a de separação entre o humano e o vegetal. A aproximação, portanto, das figuras humanas em poemas como o citado em relação a outras, não-humanas, borra as linhas construídas (social e culturalmente) entre natureza e cultura ("e penso que se enfiasse os pés na terra/ e me recusasse a me mover/aceitando o sol e a chuva/a terra e as nuvens/a noite e os pássaros/ isso seria uma espécie de felicidade"), o que instaura um tom afastado do olhar ingênuo ou idealizado para o meio natural, ao ser levantada a possibilidade de a voz poética se fundir à terra, como num processo de tentar se colocar no lugar das plantas que são cuidadas por suas mãos um distanciar-se do regimento antropocêntrico de mundo.

Esse afastamento dos moldes hierarquizantes do antropocentrismo ocorre ao longo da apresentação dos poemas, e é possível observar que existe a tentativa de horizontalização das relações, em que as vozes poéticas se misturam às paisagens construídas e definidas, aprendem com elas. Em poemas como Jardim francês, Jardim inglês, Jardim japonês, as vozes poéticas apresentam-se em primeira pessoa ("Esculpir-me", "erigir-me, "Aprendi", "Arqueio-me", "sou") - como se, a partir da observação desses espaços, elas pudessem aprender com o comportamento das plantas descritas por estarem (as vozes) inseridas nesses espaços: olhando para eles, também se aprende um pouco sobre si. Aqui também pode-se atribuir um certo 
reencantamento em relação ao meio natural, exatamente por haver a possibilidade de aprendizado que não está necessariamente atrelado a outro ser humano especialmente porque há, mais do que somente uma tentativa, a identificação humana com esses espaços e seres não humanos ("alamedas amplas me dividem/ não exatamente/ ao meio"; "sou dura e seca e quase sem enfeites/como um jardim de areia").

Além de questões referentes à presença de um reencantamento a partir da identificação mais profunda com as espécies vegetais e seus modos de vida e sobrevivência, os limites impostos pelas dicotomias entre natureza e cultura também são borrados quando se trata de certos poemas de O Livro dos Jardins apresentarem uma espécie de reconfiguração temporal, não guiada por um tempo humano, histórico, mas por uma noção de tempo ecológico. No entanto, Ana Martins Marques trata desses desaceleramentos de forma a observá-los, a refletir sobre eles no momento presente, não apenas evocando uma mundividência pré-industrial, em que a marcação temporal se dava, de fato, de outra forma: ela é trazida para a contemporaneidade porque continua a existir nos ciclos das plantas aqui apresentadas. Essa maneira, portanto, de lidar com as dinâmicas de um tempo vegetal que permanece, "independente da cotação do dólar/ das quedas das bolsas", coloca em evidência a premência de pensar essas questões temporais numa atualidade que "se havia guerras ou desastres/se um trem chocou-se no Egito/ com um ônibus escolar/ e 40 crianças morreram/ floria/ainda assim", porque, como colocado em outro poema, "todo jardim é imprevisível".

Esse movimento de repensar as amarras do tempo, utilizando-se de elementos materiais que caracterizam o nosso momento histórico, já ocorre na poética da autora em obras anteriores. Em Da arte das armadilhas (2011), por exemplo, Relógio sugere um repensar das dinâmicas da vida (comer, ler, arrumar a casa) ao estabelecer certos comportamentos e atividades como pertencentes exclusivamente ao período diurno ou noturno ("De que nos serviria/ um relógio?/ Se lavamos as roupas brancas:/é dia/ as roupas escuras: é noite"). Já em "Ícaro", de 0 
Livro das semelhanças (2015), é apresentado um tempo mitológico, pré-moderno, que se funde a uma cena contemporânea de poluição ("Os restos de suas asas/desfeitas/foram dar na praia/entre embalagens/ de plástico preservativos/garrafas vazias latas/de cerveja"). Esse jogo, portanto, estabelecido, em que se acessa ora uma temporalidade cronológica, ora uma vegetal ou préindustrial, apresenta-se como uma marca interessante na poética de Ana Martins Marques: são compreendidas algumas propostas ecológicas sugeridas, aqui e ali, em sua obra.

\section{Sérgio Medeiros: do erotismo vegetal à ética ambiental}

Seria possível ler a poesia de Sérgio Medeiros inteiramente em função de sua sensibilidade absurdista e surrealista (MCNEE, 2014, p. 71) e de seu caráter consideravelmente experimental, e obter disso material copioso para estudo e fruição. De fato, a (anti)lírica do poeta em questão vem incorporando, nos últimos anos, recursos cada vez mais variados e inovadores, como esculturas verbais, caligrafia e distribuições heterodoxas do texto na página - culminando no que ele denomina "poesia visual". No entanto, uma abordagem da obra de Medeiros que não leve em conta seus aspectos ecológicos resultaria incompleta, já que sobre eles repousa uma das principais linhas de força dessa poesia.

A influência das mitopoéticas ameríndias sobre o trabalho literário de Medeiros (cuja pesquisa acadêmica também é permeada por esse referencial) já foi explicitada por Malcolm McNee (2014, p. 72), para quem elas constituem "uma fonte de inspiração formal e conceitual para a renovação de uma poesia de invenção e experimentação radicais" ${ }^{\prime \prime}$. Essa influência assegura uma poética perspectivista que "posiciona visões indígenas do mundo natural no centro de um repensar da relação determinada pela tradição ocidental entre, de um lado, o eu humano e, do outro, o

\footnotetext{
${ }^{6}$ No original em inglês, "[Amerindian mythopoetics as] a source of formal and conceptual inspiration for the renewal of a poetry of radical invention and experimentation". Tradução nossa.
} 
meio ambiente e o outro não-humanos."7 (MCNEE, ibidem). Ou, como afirma o próprio poeta em entrevista concedida à revista Germina, em 2006:

Em todos os mitos ameríndios a fronteira entre o humano e o nãohumano é questionada ou reinventada de forma radical, surpreendente. Aprendi talvez a misturar prosa e poesia, ou todos os gêneros (teatro, roteiro, instalação), lendo esses mitos, que mesclam sem receio o humano e o animal, os deuses e as plantas. Tudo se mistura, tudo se mescla. [...] elas [as cosmogonias amazônicas] não operam com distinções ontológicas nítidas entre os humanos, de uma parte, e espécies animais e vegetais, de outra. Temos aqui uma visão de mundo monista, ou radicalmente não dualista.

Eu acredito que seja possível, a exemplo disso, uma literatura monista, que não aceite mais certas distinções dualistas. (MEDEIROS, 2006).

A assimilação das cosmogonias ameríndias desdobra-se no tratamento sui generis dado por Medeiros às formas de vida vegetais, que sobressai principalmente em Totens (2011) e O Sexo Vegetal (2009). Neste, as plantas são encaradas como seres autônomos, que se relacionam entre si, com os animais e com o ambiente à sua volta (COSTA, 2014, p. 20). Metade dos poemas da obra descreve-as nessa interação erótica com o mundo não-humano, enquanto a outra metade retrata episódios em que seres humanos participam como coadjuvantes dos fenômenos vegetais. $O$ antropocentrismo que caracteriza posturas antiecológicas se encontra, assim, duplamente superado: não apenas é concedido às plantas o estatuto de indivíduos caracterizados por sua agência em uma comunidade, como o ser humano, deslocado de sua tradicional posição no centro do universo, representa um papel periférico e acessório.

Já em Totens, Medeiros explora as possibilidades de Enrique Flor, personagem que aparece meteoricamente em Ulysses. Flor é um talentoso organista que, no romance de James Joyce, providencia música para a cerimônia religiosa de um casamento arbóreo. Medeiros, por sua vez, desenvolve na obra em questão a

\footnotetext{
${ }^{7}$ No original em inglês, "[it] suggestively positions Native American visions of the natural world at the center of a rethinking of the relationship between the human self and the nonhuman other and environment determined by the Western tradition". Tradução nossa.
} 
relação da personagem com as plantas em suas andanças pela Irlanda, Portugal e Brasil. Embora Flor seja o foco poético e narrativo em Totens, o protagonismo vegetal centrado no erotismo permanece fortemente implicado em sua atividade - e nisso reside a ligação com o projeto de $O$ Sexo Vegetal.

Em Trio pagão (2018), a seção Enrique Flor, o novo prossegue nessa linha, acompanhando o trajeto do músico que toma um avião em Lisboa, aterrissa em Dublin e cruza a cidade durante o Bloomsday para dar um concerto no final do dia. Sua "música aromática" pode ser ouvida "inequívoca" às $16 \mathrm{~h}$ vindo de uma moita, fazendo os lilases vicejarem nos arredores; a súbita abundância de vida vegetal chama atenção para a quase total ausência de plantas ao longo do itinerário de Flor. Porém, para além de questões conceituais e filosóficas, as preocupações ecológicas de Medeiros assumem em Enrique Flor, o novo uma dimensão ética explícita e urgente, que se manifesta na tematização da destruição arbórea - ou dendrocídio, para empregar um termo que concretiza o peso assassino dessa instância particular do ecocídio.

O desmatamento e o incêndio florestal, que são as duas formas de dendrocídio que permeiam a obra ${ }^{8}$, são mencionados no Prólogo: evoca-se uma "época em que as florestas de Portugal tinham desaparecido (conforme se lê no Ulysses, foi em 1904)" (MEDEIROS, 2018, p. 83), e em que "a Irlanda já estava quase tão desmatada como Portugal" (MEDEIROS, ibidem), além do contexto presente do "Brasil, que está cada vez mais desmatado" (MEDEIROS, 2018, p. 84). Um homônimo do organista Flor - o menino Enrique Flor, que origina o título dessa seção do livro é introduzido como uma das vítimas dos incêndios florestais que assolaram Portugal em junho de $2017^{9}$ ("no último verão, as suas árvores arderam pavorosamente no

\footnotetext{
${ }^{8} \mathrm{O}$ que fica particularmente evidente nas "Duas definições de Portugal (segundo um hebdomadário satírico)" (MEDEIROS, 2018, p. 102), que se resumem a caracterizar o país natal de Enrique Flor como "mais desmatado da Europa no início do século XX" e "país reflorestado na Europa mais devorado por incêndios neste início do século XXI".

${ }^{9}$ Ao atrelar sua obra a um evento ecológico historicamente documentado, Medeiros efetua um gesto não de todo diferente do que Estok (2009, p. 10) identifica no King Lear de Shakespeare, cujos aspectos ecológicos estão ligados à Little Ice Age (período de frio, chuva e ventos anormalmente intensos na Europa de 1560 a 1600).
} 
centro do país" (MEDEIROS, ibidem)), em uma manobra retórica que adiciona uma dimensão humana à catástrofe ecológica, potencializando a sensibilização.

Notícias e manchetes de vários jornais acerca desse "apocalíptico incêndio florestal" interrompem bruscamente a narrativa do percurso de Flor mais à frente, precisamente no momento em que sua música vegetal é ouvida pela primeira vez. $\mathrm{O}$ efeito de choque gerado por esse contraste (ainda mais dramático porque encerrado com um "[Silêncio cheio de aromas evanescentes]") acentua a ligação de Flor e sua arte com as mazelas ambientais, e reforça a importância ecológica das ações da personagem. Durante o concerto noturno do músico, mobilizam-se três posicionamentos ecológicos a respeito do incêndio florestal: o da banda de Flor, cuja música aborda os incêndios na Ilha da Madeira; o de um grupo de mulheres portuguesas, que se reúnem para protestar contra os incêndios em Portugal; e o do fantasma do menino Enrique Flor, que comparece ao concerto como protesto contra o incêndio que tirou sua vida. Finalmente, a canção onírica de Henry Flower (composta para um conjunto de instrumentos que inclui sons e aromas de flores) aborda liricamente os incêndios em Madeira.

O tratamento (anti)lírico do dendrocídio que pontua Enrique Flor, o novo, inscrito em uma dimensão ética que tematiza a urgência e a relevância social desse assunto (já anunciadas no Prólogo: "o que me pergunto é se as sementes voltarão a brotar ao som da sua música, quando ele tiver regressado ao seu país devastado pelo fogo/...ou quando regressar ao Brasil, que está cada vez mais devastado" (MEDEIROS, 2018, p. 84)), não se furta a propor uma práxis ecológica de combate à destruição. Tendo como modelo a "arte revolucionária [de Enrique Flor], a arte de reflorestar por meio da música" - e aqui o organista dendrólatra se converte em ativista ambiental que "ajudava com seus concertos [...] a reflorestar os parques" -, o plantio de sementes (distribuídas em massa ao fim do concerto de Flor, e semeadas como performance integrante da canção onírica que encerra o livro) surge na obra como possibilidade de restaurar a vida vegetal. 


\section{Jussara Salazar: cosmologia do não-urbanizado e o fiar-rezar-viver}

Apesar de apresentar pinceladas constantes de elementos naturais ao longo da obra ${ }^{10}$, é em Fia (2016) que essas representações da natureza assumem um caráter intimamente conectado com os pensares mais profundos acerca da ecologia, devido à particularidade geográfica à qual o processo de composição dos poemas está atrelado: Jussara Salazar desenvolveu um trabalho intenso (e extenso) de vivência entre mulheres rendeiras em Gravatá dos Gomes, povoado de Poção, município localizado no agreste pernambucano. Essa região, afetada pela presença de indústrias que terceirizam o trabalho do bordado, abriga mulheres que recebem, na venda de seus trabalhos manuais, o sustento que muitas vezes provê toda uma família. A especificidade do bordado feito na região (a renda renascença ${ }^{11}$ ), com a complexidade de tramas e pontos, funciona como fio condutor da escrita de Fia. Além disso, mais do que a técnica manual do bordado renascença estar ameaçada pela industrialização, uma realidade presente em comunidades do Poção, um modo de vida no campo, de subsistência, que tende a não fazer distinção entre trabalho, religiosidade e coletividade (uma cosmologia do não-urbanizado) também se encontra prejudicado, pois permanece afastado da lógica urbana e industrial, o que contribui para a precarização dos modos de vida de comunidades nas chamadas "zonas de sacrifício"12.

\footnotetext{
${ }^{10}$ Em entrevista à revista digital Literatura e Fechadura, em 2018, a autora afirma usar e abusar dos elementos representativos da natureza em sua poética por tê-los sempre muito próximos de si.

${ }^{11} \mathrm{~A}$ técnica da renda renascença teve sua origem na Europa no século XVI e foi introduzida no Brasil por freiras vindas de lá. Além da renda renascença, as mulheres da região do Poção fazem o bordado tradicional, tapeçaria, crochê e tecelagem. É possível conhecer um pouco mais sobre o trabalho feito pelas mulheres dessa região pelo projeto "Artesãs Têxteis de Pernambuco", uma pesquisa cultural de mapeamento afetivo das mulheres que trabalham com técnicas têxteis de bordado em Pernambuco, aprovado pelo Fundo de Incentivo à Cultura-FUNCULTURA. A pesquisa está no site "Mulheres que tecem Pernambuco".

12 As "zonas de sacrifício" são áreas geográficas que estão constantemente sofrendo com dano ambiental ou desinvestimento econômico, geralmente comunidades de baixa renda. No caso do Poção, região que foi muito próspera por conta do reconhecimento das técnicas de bordado manual, hoje sofre pela substituição desse saber pela técnica industrial.
} 
Além de tematizar, portanto, uma prática econômico-cultural da região, afetada intimamente pelos processos de industrialização, os poemas presentes na obra tratam também de complexas realidades de sobrevivência no local a partir de narrativas poéticas baseadas no discurso oral de mulheres de Gravatá dos Gomes:

O trabalho com o fio, seja na tecelagem, na costura, no bordado, ou na renda, que desde a Antiguidade é considerado socialmente como fazer feminino, emerge na poética de Jussara Salazar como elemento da subjetividade das mulheres que dominam a técnica da renda. (SOFIATI, 2018, p.2)

As subjetividades das mulheres rendeiras, expostas pelos poemas nas duas partes do livro, Cantigas de Passagem e De riscos e mapas, também estão ligadas às questões com a terra, com o ambiente físico no qual têm suas vidas inseridas ("mas são fios/de outro brilho/que as filhas da terra enlaçam/em cardumes de mãos/nas tardes perdidas/e noites escuras"). Evocando uma religiosidade intrinsecamente conectada aos símbolos da realidade árida e rural, os poemas da primeira parte de Fia apresentam uma relação profunda entre o fiar, o rezar e o viver, ações horizontalmente importantes: "e teceu/ um coração escarlate/no peito de jesus/Fia esta cantiga/e se vires a vida/fia bem depressa fia/ Fia/ esta cantiga pra passar"). A partir dessas premissas que se completam ao invés de se distanciarem, uma combinação de ecologias fica implicitamente sugerida na tríade fiar-rezar-viver (não necessariamente nessa ordem), que pode estar associada às categorias presentes em As três ecologias (2006 [1989]) de Félix Guattari. No entanto, torna-se difícil uma associação individual do fiar-rezar-viver com as ecologias mental, social e ambiental ${ }^{13}$, visto que cada um dos três processos pode assumir mais de uma característica proposta pelas ecologias de Guattari, exatamente por estarem

\footnotetext{
${ }^{13}$ Para Guattari (2006 [1989]), a ecologia mental está atrelada à reinvenção dos sujeitos a partir do repensar do corpo e dos aprofundamentos da subjetividade, da psique e do consciente; a ecologia social propõe trabalhar as relações humanas, muito calcadas ainda em demandas individuais; já a ecologia ambiental sugere o repensar das práticas humanas que causam dano extremo ao meio ambiente, visto que os desequilíbrios ambientais, se não minimizados, dependerão cada vez mais das intervenções humanas para serem mantidos (como a regulagem de oxigênio, ozônio e gás carbônico na atmosfera).
} 
intimamente entrelaçados - uma ecosofia per se ("Senhor/ que as nossas vacas andem prenhes/e as ovelhas plenas de lã/que a chuva prepare a terra/no estrume pungente da manhã/e fecunde os campos"/ Senhor dai-nos o canto/dos doidos desenganados"). Essas questões levantadas também podem ser encontradas no poema "Fábula à Nossa Senhora dos Fios", que encerra a primeira parte do livro: aqui, os princípios de fiar ("risquei um vestido/com a cor das flores/do flamboyant") associam uma sacralidade à tessitura do vestido ("teci e lavei/ na pia batismal") que é desfeito após uma lagarta de mil patas o roer. Esse inseto, apresentado no penúltimo verso do poema, vincula-se, em uma leitura metafórica, ao imprevisto da vida, fechando a tríade.

Em De riscos e mapas, segunda parte de Fia, a religiosidade ainda permanece presente (como em "Na hora das almas", "Oração à virgem dos Carreteis Gongóricos", "Nossa Senhora da Feira" e "Um sudário tecido") e mistura-se a narrativas de uma cotidianidade marcada pelas (im)possibilidades geográficas que insistem em permanecer (resistir, talvez): "verás que se ergue um mapa/ à revelia". A morte-vida, o rendado, a religiosidade marcam esse mapa como numa espécie de confirmação da tríade fiar-rezar-viver. Em "A morte da vaca", "sob a geografia santa/deste mapa/urdido entre espinhos e azuis", o animal é aconselhado pela voz poética a fugir, "que teu desterro/já foi anunciado na secura do céu", localizando a vaca, portanto, na aridez da região que abarca as narrativas de Fia. Em "Maria Pastora", o resgate da figura que dá nome ao poema, mulher que nos idos dos anos de 1930 conseguiu juntar o primeiro grupo para ensinar a técnica do bordado renascença, aprendido por ela em um convento em Olinda, reitera a importância de reconhecer a linhagem ${ }^{14}$ das mulheres rendeiras da região ("Maria pastora dos rebanhos/das primas velhas/dos vestidos pretos/dos frascos de lavanda/das bonecas de cera/da bainha descosturada"), um movimento importante a ser feito em meio ao

\footnotetext{
${ }^{14}$ A importância da ancestralidade é tematizada já no segundo poema da primeira parte do livro: "Fia esta cantiga/desfia depois/tecer e trançar/Fia esta cantiga/no tear. Em silêncio/como as tuas tias/ que teu pai foi pra roça/ vestido de noivo/e nunca voltou/Fia esta cantiga/como tua mãe um dia/sem alarde desatou".
} 
possível desaparecimento desse conhecimento por questões de interesse industrial, como já citado anteriormente. Essa vontade de permanência do conhecimento sobre o bordado, que perpassa gerações, é resumida no último dístico do poema que fecha o livro-projeto de Fia: "nossa senhora do gravatá dos gomes/ dai-nos o ponto nosso de cada dia". Afirmando a geografia (como ocorre nos poemas "À revelia", "A morte da vaca", "Tessitura" e "17 novelos brancos") e retomando a ancestralidade no processo do bordado e a vontade de manutenção dessa realidade, ancorada nas dinâmicas de fiar-rezar-viver, De riscos e mapas evoca saberes da cultura popular do Poção pertinentes à discussão ecológica, refinadamente captados pela poética de Jussara Salazar.

\section{Vinícius Lima: desconforto urbano e o reencantamento da paisagem}

Não é necessário um esforço interpretativo acima do comum para estabelecer a ecologia profunda como chave de leitura para a poesia de Vinícius Lima. Dos cinco livros que compõem sua obra poética até o momento - Herbarium (2013), Planta de Pé (2014), Começa aqui a Morada do Fogo (2016), Animais Floridos (2016) e O Sonho da Capivara (2017) -, quatro lidam explicitamente com elementos ecológicos (como pode ser percebido, inclusive, em alguns de seus títulos). Além disso, o tema se estende à pesquisa acadêmica do poeta (tendo gerado, entre outros, o site Portal de Ecopoesia, que mapeia a ecopoesia brasileira) e mesmo à sua vida pessoal (Lima é praticante da agroecologia, e atualmente reside em um sítio).

Um certo número de temas caros à ecologia profunda manifesta-se na obra poética de Lima. A crítica à moderna sociedade urbana de consumo, por exemplo, vem à tona ocasionalmente nos dois livros mais recentes: nas raras vezes em que a urbe é mencionada15, ela indefectivelmente recebe semantizações negativas. Um

\footnotetext{
${ }^{15}$ Caberia pontuar que o próprio fato de o espaço urbano ser virtualmente excluído da maioria dos poemas de Lima já constitui um posicionamento ecológico. Povoando sua obra (especialmente Animais Floridos) de uma miríade de seres não-humanos em espaços naturais, o poeta transporta o
} 
forte sentimento anti-civilização (que não se estende, entretanto, aos artefatos estéticos) determina que "a cidade é um câncer na paisagem/prédios se erguem como lápides" (LIMA, 2017, p. 33). Nessa perspectiva, passa-se de uma crítica ao modo de vida burguês - "os professores universitários/professam o nada/o motor a combustão" (LIMA, 2016, p. 24) - para o lamento pelas heranças ancestrais solapadas pela cultura de consumo - "shoppings se erguem sobre meus antepassados/feitos de flor e musgo/totens tvs" (LIMA, idem, p. 52) -, desaguando na visão apocalíptica que inaugura Animais Floridos (e que suscita ecos da filosofia desumanista de Robinson Jeffers): "e as bestas vagando pela superfície/sem a respiração dos símbolos/antes os homens domavam seus passos/e foram cuspidos do mapa" (LIMA, idem, p. 1).

Em O Sonho da Capivara, a prática da caminhada - já enaltecida por um dos pais do pensamento ecológico moderno, H. D. Thoreau - suscita reflexões antimodernas. Em suas andanças pelas ruas da cidade, o eu-lírico dos três poemas da série "caminhando" (LIMA, 2017, p. 20-22) é confrontado com o "caos sonoro", os "zumbis urbanos" e a "gente apressada" que geram repulsa (em oposição ao fascínio experimentado pelo flâneur baudelairiano da segunda metade do século XIX). Por outro lado, a caminhada também proporciona contato com formas de vida nãohumanas - "uma borboleta amarela" (LIMA, idem, p. 22), ou as "árvores que me olham como que pedindo um abraço" (LIMA, idem, p. 20) -, efetivando um reencantamento da natureza que ainda subsiste nos interstícios do espaço urbano.

Além dos posicionamentos explicitamente críticos à sociedade urbanizada pós-industrial, há poemas na obra de Lima que tematizam um modo de vida antitético ao que é imposto pela cidade - contendo, portanto, uma crítica implícita e talvez por isso mesmo ainda mais potente, já que aponta saídas e possibilidades para o problema urbano. Projeta-se, assim, um "vale escondido entre as árvores/com animais embebidos de chuva" (LIMA, 2016, p. 42), onde "as crianças correm com a capivara e colhem cogumelos" (LIMA, idem, p. 43). Ali, o ser humano pode ver sua

foco lírico para fora da esfera exclusivamente humana - aproximando-se, assim, de uma poética ecocêntrica. 
"mão toda mão/enterrada no barro" (LIMA, idem, p. 30) enquanto constrói sua "casa/feita de barro e palha" (LIMA, 2017, p. 41).

Mas, mais do que um local onde se pode levar uma vida afastada dos efeitos deletérios da sociedade de consumo e exercer a alegria que, segundo Bicca (2018, p. 165), "é parte do ideário ecofilosófico", o retiro rural faculta um contato profundo com a natureza não-humana. Profundo, porque implica um engajamento corporal com o espaço e os seres que nele habitam, regido por estímulos multissensoriais. Dessa forma, audição, paladar, tato e olfato captam constantemente signos naturais, como mostram os excertos seguintes: "entre os respiros da fogueira/forte fragrância frutada" (LIMA, 2016, p. 3); "molho os pés rachados" (LIMA, idem, p. 29); "quando o sol, o ar, o som da seiva/nos atravessa cada poro da pele" (LIMA, idem, p. 32); "ouçam a voz dos troncos/tocados pela tempestade" (LIMA, idem, p. 33); "o carvalho cospe em mim sua doce resina" (LIMA, idem, p. 43).

Essa interação holística com a natureza não-humana resulta em dois desdobramentos: por um lado, o eu-lírico se identifica com ela, seja apagando as fronteiras de seu corpo - "meu corpo não tem limites transborda transparente" (LIMA, 2017, p. 31) -, seja assumindo identidades e vozes não-humanas: "eu sou um cervo/uma roseira ampla/árvore que renova seus galhos/e deita raízes" (LIMA, 2016, p. 28), "sou uma caverna/uma música sísmica" (LIMA, idem, p. 33). Por outro lado, visões de corpos que se hibridizam, adquirindo traços de outras espécies, permeiam os poemas de Animais Floridos: "folhas raízes aortas coronárias" (LIMA, 2016, p. 1); "barba crespa de hera", LIMA, idem, p. 28); "estrela explodida dentro do corpo" (LIMA, idem, p. 32); "útero rochoso/da terra" (LIMA, idem, p. 33); "de mim/de dentro/do sexo/cresce/árvore/ vertical" (LIMA, idem, p. 74); "vagina/feita de mata e musgo" (LIMA, idem, p. 77).

O aspecto potencialmente mais interessante, de um ponto de vista ecológico, na poesia de Lima é a projeção de paisagens naturais oníricas que agenciam os seres não-humanos e o espaço que habitam em configurações particulares. Regidas, todavia, pelo onirismo, elas não se limitam a assinalar as interrelações que se 
processam na natureza não-humana: atribuem-Ihe, pelo contrário, um caráter mítico que beira o surreal. Assim, por exemplo, "descem/gritando/sobre o bosque/os peixes negros" (LIMA, 2016, p. 75), e "cavalos correm/com as bocas cheias de pregos/e os cascos afiados em estrelas" (LIMA, idem, p. 21); ou, ainda, "oh lobo azul da cabeça de prata oh árvore infinita que sustenta o mundo as estrelas nos empurram pra dentro da terra pro sono profundo da terra enquanto vaga-lumes nos guiam a noite engolindo" (LIMA, idem, p. 45), e "desenharemos com dedos mágicos nossas sombras em uma árvore e dela brotarão nossos sonhos e um filhote de lobo abrirá o mundo com seu canto de fogo e viver será leve como uma flor de acácia adormecida neste vale-útero" (LIMA, 2017, p. 42).

As "paisagens sonhadas" de Lima são essencialmente dinâmicas, negando a visão estática da natureza que caracteriza uma postura ecológica rasa. Somado às tonalidades místicas e surreais que trazem à natureza não-humana uma dimensão estética bastante peculiar (e não de todo distante da que se observa nas mitopoéticas ameríndias), esse dinamismo que evidencia o profundo entrelaçamento entre as formas de vida efetiva um reencantamento da natureza - tendendo, pela sua inflexão mitológica, ao projeto de ressacralização associado à ecologia profunda (BICCA, 2018, p. 163).

\section{Referências}

BICCA, Luiz. Vida cotidiana e pensamento ecológico. Rio de Janeiro: Ed. PUC-Rio: 7 Letras, 2018.

COSTA, Júlia de Marins. Comunicação e meio ambiente: análise ecocrítica da ecopoesia e do jornalismo ambiental no Brasil. Rio de Janeiro, 2014. Trabalho de conclusão de curso. $76 \mathrm{pp}$.

ESTOK, Simon C. Theorizing in a Space of Ambivalent Openness: Ecocriticism and Ecophobia. Oxford: Oxford University Press, 2009.

FRÓES, Leonardo. A Fábula da Cebola. Entrevista cedida a Alberto Pucheu, Ricardo Lima \& Sérgio Cohn. Revista Azougue, São Paulo, n. 8, pp. 5-11, abril de 2003. 
Disponivel em: <https://www.germinaliteratura.com.br/literatura_esp_froes6.htm>. Acesso em: 28 abril 2020.

GIFFORD, Terry. A Ecocrítica na mira da crítica atual. Rio de Janeiro: Terceira Margem, jul. 2009, p. 244-261. Disponivel em: $<$ https://revistas.ufrj.br/index.php/tm/article/view/11049/ 8065>. Acesso em: 08 de abril de 2020.

GLOTFELTY, Cheryl. Introduction: Literary studies in an age of Environmental Crisis. In: GLOTFELTY, Cheryl; FROMM, Harold (org.). The Ecocriticism Reader. Georgia: The University of Georgia Press, 1996.

GUATTARI, Félix. As três ecologias. São Paulo: Papirus, 2006 [1989].

KRENAK, Ailton. Ideias para adiar o fim do mundo. São Paulo: Companhia das Letras, 2019.

LIMA, Vinícius. Animais Floridos. Belo Horizonte: Anome Livros, 2016.

O Sonho da Capivara. Londrina: Rubra Cartoneira Editorial, 2017.

MAROUES, Ana Martins. O Livro dos Jardins. São Paulo: Editora Quelônio, 2019. . O Livro das Semelhanças. São Paulo: Companhia das

Letras, 2015. . Da Arte das Armadilhas. São Paulo: Companhia das

Letras, 2011. . A vida Submarina. Belo Horizonte: Scriptum, 2009.

. Natureza em miniatura. Entrevista concedida a Beatriz Goulart. Revista Bravo!, 2019. Disponível em: <https://medium.com/revistabravo/ana-martins-marques-com-ela-ningu\% $0 \mathrm{C}_{3} \%$ Agm-pode-e6d302C79fo8>. Acesso em: 29 abril 2020.

MCNEE, Malcolm. The Environmental Imaginary in Brazilian Poetry and Art. Nova lorque: Palgrave Macmillan, 2014.

MEDEIROS, Sérgio. Trio Pagão. São Paulo: lluminuras, 2018.

. Entrevista cedida a Rodrigo de Souza Leão. Revista Germina Literatura, v. 2 no 4 , novembro/dezembro 2006. Disponível em: < 
https://www.germina literatura.com.br/pcruzadas_sm_nov2006.htm>. Acesso em 29 abril 2020.

NOGUEIRA, Clara. Mulheres que Tecem Pernambuco. 2018. Disponível em: <http://mulheresquetecempe.com.br/\#inicio>. Acesso em: 10 abr. 2020.

SALAZAR, Jussara. Fia. São Paulo: V. de Moura Mendonça-livros (selo Demônio Negro), 2016.

_. Entrevista concedida a Fernando Andrade. Revista digital Literatura e Fechadura, 2018: Disponível em: <https://www.literaturaefechadura.com.br/2018/ 07/17/fernando-andradeentrevista-a-poeta-jussara-salazar/>. Acesso em: 29 abril 2020.

SILVA JÚNIOR, José Juvino da. Leonardo Fróes e as cartografias das vertigens selvagens: a poesia, o mundo natural e o sagrado. Tese (Doutorado) - Universidade Federal de Pernambuco, Centro de Artes e Comunicação. Letras, 2016. 176 f.

SOFIATI, Luana. "Teço artérias como labirinto": o corpo como experiência histórica na poética de Jussara Salazar em Fia. In: Congresso Internacional da Associação Brasileira de Literatura Comparada - Abralic, julho, 2018, Porto Alegre, RS. Disponível em: <http://www.abralic.org.br/anais/arquivos/2018_1547745632.pdf>. Acesso em 08/04/2020.

SOUZA JUNIOR, Mauro Cezar de. O Chamado selvagem da sobrenatureza: Leonardo Fróes e Gary Snyder. Revista Garrafa, v. 4 n 8, 2006. Disponível em: < https://revistas. ufrj.br/index.php/garrafa/article/view/7494/o>. Acesso em 29 abril 2020.

\footnotetext{
' Mariana Cristina Pinto MARINO: Doutoranda em Estudos Literários na Universidade Federal do Paraná (UFPR) e membra do Grupo de Estudos Ecocríticos (GECO). mariana.cmarino@gmail.com

ii Yuri Amaury Pires MOLINARI: Doutorando em Estudos Literários na Universidade Federal do Paraná (UFPR) e membro do Grupo de Estudos Ecocríticos (GECO).

Yuri amaury@yahoo.com.br
} 